\title{
Dinâmicas de trânsito e degradação da fibra em detergente neutro em bovinos alimentados com forragem tropical de baixa qualidade e compostos nitrogenados
}

\author{
[Transit and degradation dynamics of neutral detergent fiber in cattle fed low-quality tropical \\ forage and nitrogenous compounds] \\ I. Lazzarini $^{1,3}$, E. Detmann
2,4*
M.A. Couza ${ }^{1,3}$, F.A. Oliveira \\ ${ }^{1}$ Aluno de pós-graduação - UFV - Viçosa, MG \\ ${ }^{2}$ Departamento de Zootecnia - UFV \\ Av. P.H. Rolfs, $\mathrm{s} / \mathrm{n}$ \\ 36570-000 - Viçosa, MG \\ ${ }^{3}$ Bolsista da CAPES \\ ${ }^{4}$ Bolsista do CNPq
}

\begin{abstract}
RESUMO
Avaliaram-se as dinâmicas de trânsito e degradação da fibra em detergente neutro (FDN) em bovinos alimentados com forragem tropical de baixa qualidade e compostos nitrogenados. Foram utilizadas cinco novilhas Holandês x Zebu fistuladas no rúmen. A alimentação volumosa basal dos animais foi constituída por feno de capim-braquiária (Brachiaria decumbens Stapf.), com 5,08\% de proteína bruta (PB), com base na matéria seca (MS), fornecido ad libitum. Os cinco tratamentos avaliados foram definidos de acordo com o nível de suplementação proteica $(0,3,5,7$ e 9 pontos percentuais acima do nível de PB da forragem). Como fonte de compostos nitrogenados, empregou-se mistura de ureia:sulfato de amônia:albumina $(4,5: 0,5: 1,0)$. O experimento foi estruturado segundo delineamento em quadrado latino 5 x 5 . Os níveis médios de PB nas dietas foram de 5,28; 8,08; 9,82; 11,87 e 13,63\%, com base na MS. Verificou-se elevação linear $(\mathrm{P}<0,05)$ da fração potencialmente degradável da FDN até o nível de $8,62 \%$ de $\mathrm{PB}$, com platô estimado de $47,92 \%$ da FDN. Verificou-se efeito quadrático $(\mathrm{P}<0,05)$ sobre a taxa de degradação da fração potencialmente degradável da FDN em função dos níveis de PB da dieta, com máxima resposta estimada sobre $13,39 \%$ de PB. O fluxo ruminal de partículas fibrosas apresentou relação linear-response-plateau em função do nível de $\mathrm{PB}$ na dieta $(\mathrm{P}<0,05)$, com ponto crítico para o início do platô sobre 7,59\% de PB.
\end{abstract}

Palavras-chave: Brachiaria decumbens, repleção ruminal, suplementação, taxa de degradação, taxa de passagem

\begin{abstract}
Rumen transit and degradation dynamics of neutral detergent fiber (NDF) in cattle fed low-quality tropical forage and nitrogenous compounds were evaluated. Five crossbred heifers fitted with rumen cannulae were used. The animals were fed ad libitum with signal grass (Brachiaria decumbens Stapf.) hay, which had crude protein (CP) content of 5.08\% in dry matter (DM). The five treatments were defined according to the level of $C P$ in the diet $(0,3,5,7$, and 9 percentile points above the $C P$ level of the roughage). The supplement was a mixture of urea, ammonium sulfate, and albumin (4.5:0.5:1.0, respectively). The experiment was carried out according to a $5 \times 5$ Latin square design. The average $C P$ levels in the diets were: $5.28,8.08,9.82,11.87$, and $13.63 \%$ in DM basis. The potentially degradable
\end{abstract}

Recebido em 11 de setembro de 2008

Aceito em 10 de março de 2009

*Autor para correspondência (corresponding author)

E-mail: detmann@ufv.br

Apoio: CNPq, FAPEMIG - Programa Pesquisador Mineiro. 
fraction of NDF was linearly increased $(P<0.05)$ by $C P$ levels in diet until $8.62 \% C P$. From this point, there was stabilization of estimates $(47.92 \%$ of NDF). The degradation rate of potentially degradable $N D F$ showed a quadratic response $(P<0.05)$ to $C P$ levels, with maximal response at $13.39 \%$ of $C P$. The ruminal rate of passage of fibrous particles showed a linear-response-plateau $(P<0.05)$ according to $C P$ levels in the diet, with plateau beginning at $7.59 \%$ of $C P$.

Keywords: Brachiaria decumbens, rumen fill, supplementation, degradation rate, passage rate

\section{INTRODUÇÃO}

Apesar do elevado potencial de produção anual e do baixo custo, as gramíneas tropicais, durante a estação seca do ano, apresentam baixa eficiência de utilização, devido ao espessamento e aumento da lignificação da parede celular, o que compromete sua qualidade como alimento para ruminantes. Consequentemente, a forragem decresce rapidamente em digestibilidade, aumentando o tempo de retenção ruminal, acarretando redução no consumo voluntário e ocasionando comprometimento no desempenho animal.

Embora nessas condições as carências nutricionais sejam de natureza múltipla, a deficiência proteica faz-se prioritária, implicando condições subótimas no ambiente ruminal (Ørskov, 2000) e limitando, principalmente, a atividade microbiana sobre os carboidratos fibrosos da forragem de baixa qualidade.

Sendo a dimensão das frações potencialmente degradável e indegradável característica do substrato, alterações no ambiente ruminal provocam variações sobre a taxa de degradação pelos microrganismos (Ørskov, 2000). Esses efeitos apresentam maior impacto em condições tropicais com relação à fibra em detergente neutro (FDN), devido ao seu papel como principal substrato energético para o crescimento e como fator determinante do processo de repleção ruminal, o qual se amplia à medida que decresce a qualidade da forragem (Vieira et al., 1997). Este comportamento implica, diretamente, redução do consumo voluntário por ruminantes, retardando a introdução de novos componentes potencialmente degradáveis no ambiente ruminal.

Alterações positivas no escape de partículas do ambiente ruminal estão associadas à utilização de suplementos nitrogenados em forragens de baixa qualidade, relacionando-se fortemente à ampliação do consumo total pelo animal
(McCollun e Galyean, 1985). É importante ressaltar que os processos de degradação e trânsito ruminal devem ser avaliados de forma integrada no sentido de que, à medida que se amplia a velocidade de utilização dos compostos potencialmente degradáveis, reduz-se o tempo necessário para que a partícula alcance a faixa de gravidade específica para a remoção do rúmen (Allen, 1996).

A suplementação proteica mostra-se eficiente, pois oferece condições para que os microrganismos utilizem eficientemente os carboidratos fibrosos presentes na forragem basal. Todavia, há necessidade de se quantificar de forma exata os benefícios da alimentação de bovinos contendo compostos nitrogenados suplementares quando a produção se baseia em dietas ricas em forragem de baixa qualidade, para que seja, então, permitida a otimização na utilização de suplementos nitrogenados.

Assim, o objetivo deste trabalho foi avaliar as dinâmicas de trânsito e a degradação ruminal da FDN em bovinos alimentados com forragem tropical de baixa qualidade suplementada com compostos nitrogenados.

\section{MATERIAL E MÉTODOS}

Foram utilizadas cinco novilhas Holandês $\mathrm{x}$ Zebu, com peso vivo (PV) médio inicial de $209 \pm 13 \mathrm{~kg}$, fistuladas no rúmen, mantidas em baias individuais cobertas, com piso de concreto, comedouro e acesso irrestrito à água e à mistura mineral. A alimentação volumosa basal foi constituída por feno de capim-braquiária (Brachiaria decumbens Stapf.) de baixa qualidade, com nível médio de proteína bruta (PB) de 5,08\%, com base na matéria seca (MS), o qual foi fornecido ad libitum.

Os cinco tratamentos avaliados foram definidos de forma a elevar-se o nível de PB da forragem em $0,3,5,7$ e 9 pontos percentuais, com base na MS. Como fonte de compostos nitrogenados, 
empregou-se mistura de ureia, sulfato de amônia e albumina, nas proporções de 4,5:0,5:1,0, respectivamente. Os suplementos foram calculados com base no consumo de MS computado no dia anterior e introduzidos no rúmen dos animais. A escolha dos componentes do suplemento utilizado deu-se com base na ausência de carboidratos, permitindo avaliar os efeitos da suplementação com compostos nitrogenados sem que alguma fonte suplementar de fibra ou energia fosse adicionada à dieta. A introdução de albumina no suplemento buscou suprir as necessidades microbianas em termos de proteína verdadeira degradável no rúmen, permitindo-se o fornecimento de substratos essenciais, como ácidos graxos voláteis de cadeia ramificada. A alimentação volumosa foi fornecida diariamente ad libitum, permitindo-se, aproximadamente, $10 \%$ de sobras, sendo fracionada em duas porções de mesmo peso, as quais foram fornecidas diariamente às $8 \mathrm{~h}$ e $16 \mathrm{~h}$. No momento do fornecimento do volumoso, os suplementos foram introduzidos no rúmen dos animais em duas porções de mesmo peso. O volumoso ofertado e as respectivas sobras foram quantificados diariamente.

O experimento foi constituído de cinco períodos experimentais, com 16 dias cada, sendo os cinco primeiros dias destinados à adaptação dos animais aos níveis de suplementação.

Para quantificação e avaliação do consumo voluntário de MS e FDN, foram considerados os alimentos fornecidos entre o sexto e o nono dia de cada período experimental, sendo as sobras computadas entre o sétimo e o $10^{\circ}$ dia. As amostras de volumoso e as sobras obtidas foram processadas em moinho de facas (1mm), acondicionadas em potes plásticos e armazenadas para posterior análise.

Para avaliação da concentração de nitrogênio amoniacal ruminal (NAR), realizaram-se, no sexto dia do período experimental, coletas de líquido ruminal às $4 \mathrm{~h}, 8 \mathrm{~h}, 12 \mathrm{~h}, 16 \mathrm{~h}, 20 \mathrm{~h}$ e $24 \mathrm{~h}$. As amostras foram coletadas manualmente na interface líquido:sólido do ambiente ruminal e filtradas por camada tripla de gaze. Em seguida, separou-se alíquota de $40 \mathrm{~mL}$, a qual foi fixada com $1 \mathrm{~mL}$ de $\mathrm{H}_{2} \mathrm{SO}_{4}(1: 1)$ e congelada $\left(-20^{\circ} \mathrm{C}\right)$.

Do $11^{\circ}$ ao $16^{\circ}$ dia do período experimental, realizou-se procedimento para avaliação da cinética de trânsito gastrintestinal de partículas fibrosas, que se baseou no fornecimento de indicador externo, em procedimento de dose única (Ellis et al., 1994), sendo empregado o cromo mordentado à fibra, produzido conforme descrição de Udén et al. (1980). A base fibrosa para produção do indicador foi retirada de amostras do volumoso fornecido.

Foram fornecidos, para cada animal, $100 \mathrm{~g}$ de fibra mordente, diretamente no rúmen, às $8 \mathrm{~h}$ do $11^{\circ}$ dia, sendo as amostras fecais obtidas diretamente do reto dos animais em $0,3,6,9,12$, $15,18,21,24,30,36,42,48,60,72,84,96,120$ e 144 horas após o fornecimento do indicador. As amostras foram secas em estufa de ventilação forçada $\left(60^{\circ} \mathrm{C} / 72\right.$ horas $)$ e processadas em moinho de facas $(1 \mathrm{~mm})$. Simultaneamente a essa avaliação, foi realizado procedimento de incubação ruminal in situ para quantificação dos eventos da dinâmica de degradação ruminal dos carboidratos fibrosos.

Amostras de feno foram processadas em moinho de facas $(2 \mathrm{~mm})$. O material foi acondicionado em sacos de tecido não-tecido (TNT $-100 \mathrm{~g} / \mathrm{m}^{2}$ ), obedecendo-se à relação de $20 \mathrm{mg}$ de $\mathrm{MS} / \mathrm{cm}^{2}$ de superfície. As amostras, em duplicata, foram introduzidas no rúmen dos animais. Os tempos de incubação avaliados foram: $0,3,6,9,12,18$, 24, 30, 36, 48, 72, 96 e 120 horas. A disposição das amostras em relação aos tempos de incubação foi realizada de forma inversa, permitindo a retirada de todas as amostras simultaneamente, sendo submetidas à lavagem até o clareamento total da água, conduzidas à estufa de ventilação forçada $\left(60^{\circ} \mathrm{C} / 72\right.$ horas $)$ e, posteriormente, analisadas em relação aos teores de FDN em equipamento analisador de fibras ${ }^{1}$.

As amostras de feno foram avaliadas quanto aos teores de MS, matéria orgânica (MO), $\mathrm{PB}$, extrato etéreo (EE) e lignina $\left(\mathrm{H}_{2} \mathrm{SO}_{4} 72 \% \mathrm{p} / \mathrm{p}\right)$, segundo técnicas descritas por Silva e Queiroz (2002). Os teores de fibra em detergente neutro (FDN) foram estimados segundo recomendações de Mertens (2002). As amostras de suplemento foram analisadas quanto aos teores de MS, MO e PB (Silva e Queiroz, 2002) (Tab. 1).

${ }^{1}$ Ankom220 - Ankom Technology Corp. - Fairpot, NY, EUA. 
Tabela 1. Composição química do feno e do suplemento

\begin{tabular}{lrc}
\multicolumn{1}{c}{ Item } & Feno & Suplemento \\
\hline MS (\%MN) & 87,74 & 96,70 \\
MO (\%MS) & 94,35 & 98,75 \\
PB (\%MS) & 5,08 & 235,34 \\
EE (\%MS) & 0,62 & --- \\
FDN (\%MS) & 83,55 & --- \\
Lignina (\%MS) & 7,51 & --- \\
\hline
\end{tabular}

MS: matéria seca; MO: matéria orgânica; PB: proteína bruta; EE: extrato etéreo; FDN: fibra em detergente neutro; $\mathrm{MN}$ : matéria natural.

A concentração de NAR no líquido ruminal foi estimada pelo sistema micro-Kjeldahl, sem digestão ácida e utilizando-se como base para destilação o hidróxido de potássio $(2 \mathrm{~N})$, após centrifugação prévia da amostra a $1000 \mathrm{x}$ g por 15 minutos. As concentrações obtidas nos diferentes tempos de amostragem foram combinadas por animal, produzindo-se, ao final, valor único, representativo da média diária de concentração de NAR.

As amostras de fezes relativas aos procedimentos para quantificação dos parâmetros da cinética de trânsito foram analisadas quanto aos teores de MS (Silva e Queiroz, 2002) e cromo (Williams et al., 1962).

Os parâmetros da cinética de trânsito foram estimados por intermédio do ajustamento do modelo $\Gamma(2)$ tempo-dependente descrito por Ellis et al. (1994) à curva de excreção fecal do indicador:

$C_{t}=Z \times(t-\tau) \times L \times \exp [-L \times(t-\tau)]$, em que: $\mathrm{Ct}=$ concentração fecal do indicador no tempo " $\mathrm{t}$ " (ppm); $\mathrm{t}=$ tempo após o fornecimento do indicador $(\mathrm{h})$; $\mathrm{L}=$ parâmetro taxa tempodependente relativo ao fluxo ruminal de partículas (h-1); $\mathrm{Z}=$ parâmetro sem interpretação biológica direta (ppm.h); e $\tau=$ tempo de trânsito intestinal (h).

Os tempos médios de retenção no rúmen-retículo e no trato gastrintestinal total foram estimados pelas equações seguintes, segundo Ellis et al. (1994):

$$
\begin{aligned}
& T M R R=2 / L \text { e } \\
& T M R T=T M R R+\tau,
\end{aligned}
$$

em que: TMRR $=$ tempo médio de retenção no rúmen-retículo $(\mathrm{h}) ; \mathrm{TMRT}=$ tempo médio de retenção total $(\mathrm{h})$; e $\mathrm{L}$ e $\tau$ como definidos anteriormente.

Os perfis de degradação da FDN foram interpretados por intermédio do modelo logístico descrito por Van Milgen et al. (1991):

$R_{t}=B \times(1+\lambda \times t) \times \exp (-\lambda \times t)+I$

em que: $\mathrm{Rt}=$ resíduo não-degradado de FDN no tempo " $\mathrm{t}$ " $(\%) ; \mathrm{B}=$ fração potencialmente degradável (\%); I = fração indegradável (\%); e $\lambda$ $=$ taxa fracional conjunta de latência $\mathrm{e}$ degradação $\left(\mathrm{h}^{-1}\right)$.

A taxa fracional de degradação da FDN foi estimada a partir de $\lambda$, utilizando-se as propriedades da distribuição $\Gamma(2)$ (Ellis et al., 1994):

$k d=0,59635 \times \lambda$

em que: $\mathrm{kd}=$ taxa fracional de degradação da fração potencialmente degradável da $\operatorname{FDN~}\left(\mathrm{h}^{-1}\right)$.

As estimativas de latência discreta foram obtidas segundo derivações de Vieira et al. (1997):

$L A G=\frac{R(0)-R\left(t_{i}\right)}{R^{\prime}\left(t_{i}\right)}+t_{i}$,

em que: $\mathrm{LAG}=$ latência discreta $(\mathrm{h}) ; \mathrm{R}(0)=$ resíduo de FDN não-degradado em $\mathrm{t}=0$ (\%); $\mathrm{R}(\mathrm{ti})=$ resíduo não-degradado de FDN obtido no ponto de inflexão da curva de degradação (\%); $\mathrm{R}^{\prime}\left(\mathrm{t}_{\mathrm{i}}\right)=$ derivada da curva ajustada de degradação para o ponto de inflexão (máxima taxa de degradação do substrato) $\left(\mathrm{h}^{-1}\right) ; \mathrm{e} \mathrm{t}_{\mathrm{i}}=$ tempo equivalente ao ponto de inflexão da curva de degradação (h).

Os valores de $t_{i}$ foram obtidos segundoVan Milgen et al. (1991):

$t_{i}=1 / \lambda$,

As frações B e I foram expressas na forma padronizada, segundo sugestões de Waldo et al. (1972):

$B p=B /(B+I)$
$I p=I /(B+I)$

A fração efetivamente degradada da FDN foi obtida em adaptação às sugestões de Ørskov e McDonald (1979), segundo a equação: 


$$
\mathrm{FED}=\lim _{\mathrm{t} \rightarrow \infty} \int_{0}^{\mathrm{t}}\left[\mathrm{f}(\mathrm{t}) \times\left(-\frac{\mathrm{dRt}}{\mathrm{dt}}\right)\right] \mathrm{dt},
$$

em que: FED = fração efetivamente degradada da FDN $(\%) ; f(\mathrm{t})=$ função relativa ao deslocamento de sólidos no ambiente ruminal.

A função $f(\mathrm{t})$ foi obtida por re-parametrização de (1), reinterpretando-se o perfil excretório obtido de partículas emergentes para partículas residentes (Ellis et al., 1994):

$$
f(t)=(1+L \times t) \times \exp (-L \times t),
$$

As estimativas do efeito de repleção ruminal da FDN foram obtidas por adaptações às proposições de Waldo et al. (1972), segundo as equações:

$$
\begin{aligned}
& R R_{1}=\lim _{t \rightarrow \infty} \int_{0}^{t}[B p \times(1+\lambda \times t) \times \exp (-\lambda \times t) \times(1+L \times t) \times \exp (-L \times t)] d t \\
& R R_{2}=\lim _{t \rightarrow \infty} \int_{0}^{t}[I p \times(1+L \times t) \times \exp (-L \times t)] d t
\end{aligned}
$$$$
R R_{t}=R R_{1}+R R_{2}
$$

em que: $\mathrm{RR}_{\mathrm{t}}=$ efeito de repleção ruminal total (h); $R_{1}=$ efeito de repleção ruminal atribuído à fração potencialmente degradável da FDN (h); e $\mathrm{RR}_{2}=$ efeito de repleção ruminal atribuído à fração indegradável da FDN (h).

O experimento foi analisado segundo delineamento em quadrado latino 5 x 5 , com cinco tratamentos, cinco animais e cinco períodos experimentais. Para efeito de interpretação dos efeitos de tratamentos, empregaram-se os níveis médios de $\mathrm{PB}$ nas dietas equivalentes a cada nível de suplementação. O comportamento das médias foi interpretado com o auxílio de técnicas de regressão e correlação lineares (Myers, 1990). Todos os procedimentos de regressão não-linear aplicados para o ajustamento de modelos foram realizados segundo o algoritmo iterativo de Gauss-Newton (Souza, 1998).

Todos os procedimentos estatísticos foram realizados por intermédio do programa SAS/1989, adotando-se 0,05 como nível crítico de probabilidade para o erro tipo I.

\section{RESULTADOS E DISCUSSÃO}

Os níveis médios de $\mathrm{PB}$ nas dietas, produzidos a partir da razão entre consumo total de PB (forragem e suplemento) e o consumo total de

MS, foram de 5,28\%, 8,08\%, 9,82\%, 11,87\% e $13,63 \%$, com base na MS, para os níveis de suplementação $0,3,5,7$ e 9 pontos percentuais, respectivamente.

$\mathrm{Na}$ Tab. 2 são apresentadas as estimativas dos parâmetros das dinâmicas de degradação e trânsito ruminal e consumo de FDN e da concentração de NAR em função dos diferentes níveis de PB na dieta.

Os efeitos da suplementação com compostos nitrogenados sobre a fração potencialmente degradável da FDN (Bp) podem ser visualizados por intermédio da função linear-responseplateau (LRP) apresentada na Fig. $1(\mathrm{P}<0,05)$. Tal relação permite evidenciar a elevação de $\mathrm{Bp}$ ao patamar de $47,92 \%$ da FDN a partir do nível de $8,62 \%$ de PB na dieta. Comportamento similar, mas com relação linear inversa, foi verificado sobre as estimativas da fração indegradável padronizada da FDN (Ip) $(\mathrm{P}<0,05)$ $(\hat{\mathrm{Y}}=88,8554-4,264 \mathrm{X} ; \forall \mathrm{X} \leq 8,6248 ; \hat{\mathrm{Y}}=$ 52,0767; $\left.\forall \mathrm{X}>8,6248 ; \mathrm{R}^{2}=0,9809\right)$. Esse comportamento se justifica pelo fato de Bp e Ip serem complementares, e aparentemente contradiz a definição de fração potencialmente degradável (e indegradável), uma vez que a dimensão dessa é característica única e exclusiva do substrato (Ørskov, 2000), não podendo ser afetada por características do meio de crescimento microbiano. 
Tabela 2. Médias de quadrados mínimos e coeficientes de variação (CV) para as estimativas dos parâmetros das dinâmicas de trânsito e degradação da FDN, para o consumo de FDN (CFDN) e para a concentração de nitrogênio amoniacal ruminal (NAR) em função dos níveis de proteína bruta PB na dieta

\begin{tabular}{|c|c|c|c|c|c|c|}
\hline \multirow{2}{*}{ Item } & \multicolumn{5}{|c|}{ Nível de PB (\%) } & \multirow{2}{*}{$\mathrm{CV}(\%)$} \\
\hline & 5,28 & 8,08 & 9,82 & 11,87 & 13,63 & \\
\hline BP (\%) & 33,66 & 45,61 & 46,76 & 49,20 & 47,81 & 11,7 \\
\hline Ip (\%) & 66,34 & 54,39 & 53,24 & 50,80 & 52,19 & 9,4 \\
\hline $\mathrm{kd}\left(\mathrm{h}^{-1}\right)$ & 0,1761 & 0,1826 & 0,1804 & 0,2158 & 0,1863 & 26,8 \\
\hline LAG (h) & 1,04 & 0,98 & 0,94 & 0,81 & 0,95 & 26,1 \\
\hline FED (\%) & 32,97 & 44,92 & 46,08 & 48,38 & 47,03 & 11,9 \\
\hline $\mathrm{L}\left(\mathrm{h}^{-1}\right)$ & 0,0117 & 0,0152 & 0,0144 & 0,0150 & 0,0148 & 19,3 \\
\hline$\tau(h)$ & 6,10 & 5,93 & 6,58 & 6,77 & 6,79 & 17,1 \\
\hline TMRR (h) & 193,41 & 133,49 & 153,03 & 138,86 & 140,20 & 23,7 \\
\hline TMRT (h) & 199,51 & 139,42 & 159,61 & 145,63 & 146,99 & 23,3 \\
\hline $\mathrm{RR}_{1}(\mathrm{~h})$ & 2,14 & 2,92 & 2,86 & 2,56 & 3,01 & 30,0 \\
\hline $\mathrm{RR}_{2}(\mathrm{~h})$ & 115,85 & 70,92 & 75,88 & 68,47 & 72,04 & 21,2 \\
\hline $\mathrm{RR}_{\mathrm{t}}(\mathrm{h})$ & 117,99 & 73,81 & 78,75 & 71,02 & 75,03 & 20,2 \\
\hline $\begin{array}{c}\text { CFDN (g/kg } \\
\text { PV) }\end{array}$ & 12,48 & 14,97 & 15,82 & 16,45 & 15,23 & 14,2 \\
\hline NAR (mg/dL) & 4,03 & 11,22 & 10,39 & 17,43 & 24,54 & 74,1 \\
\hline
\end{tabular}

Bp: fração potencialmente degradável padronizada da FDN; Ip: fração indegradável padronizada da FDN; kd: taxa de degradação da fração potencialmente degradável da FDN; LAG: latência discreta; FED: fração efetivamente degradada da FDN; L: parâmetro taxa tempo-dependente relativo ao fluxo ruminal de partículas fibrosas; $\tau$ : tempo de trânsito intestinal; TMRR: tempo médio de retenção no rúmen-retículo; TMRT: tempo médio de retenção total; $\mathrm{RR}_{1}$ : efeito de repleção ruminal da fração potencialmente degradável da FDN; $R_{2}$ : efeito de repleção ruminal da fração indegradável da FDN; $\mathrm{RR}_{\mathrm{t}}$ : efeito de repleção ruminal total da FDN.

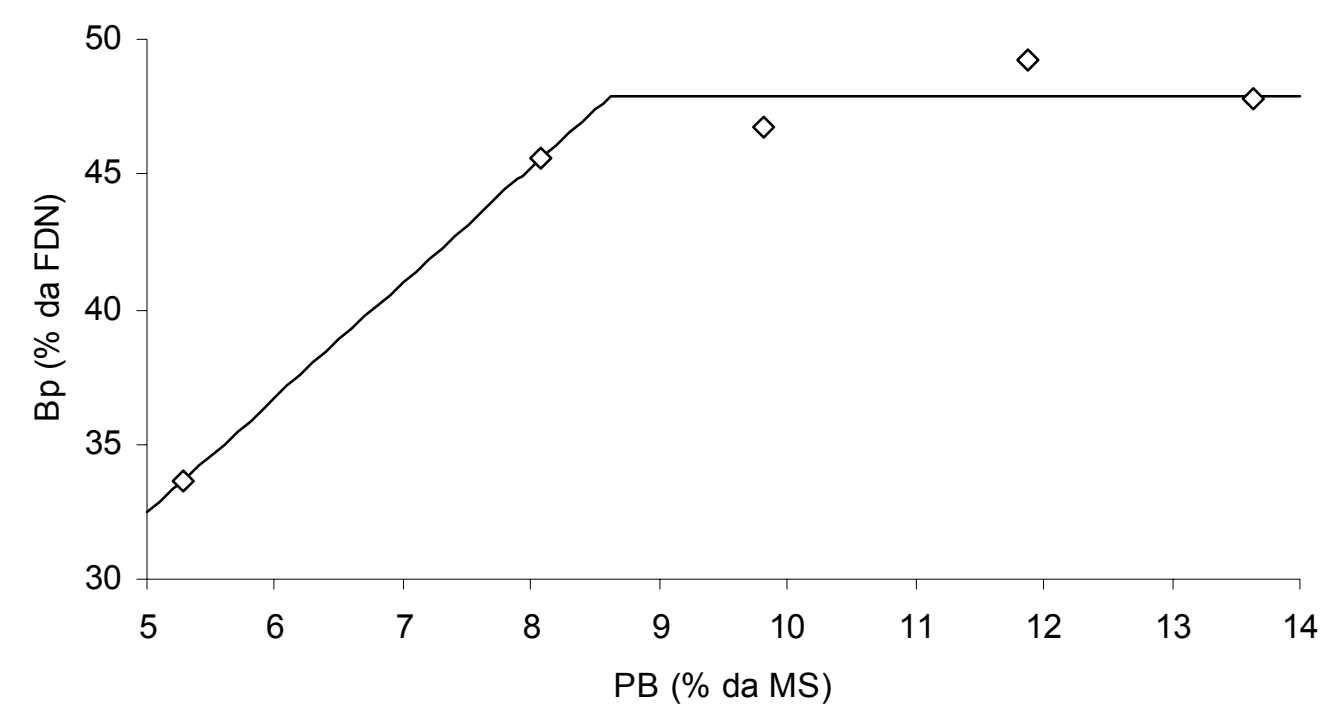

Figura 1. Comportamento descritivo e função ajustada para a relação entre o nível de proteína bruta da dieta $(\mathrm{PB})$ e a estimativa da fração potencialmente degradável padronizada (Bp) da fibra em detergente neutro (FDN) $\left(\hat{Y}=11,1446+4,264 X ; \forall X \leq 8,6248 ; \hat{Y}=47,9233 ; \forall X>8,6248 ; R^{2}=0,9809\right)$. 
Contudo, segundo Van Soest (1994), as exigências de compostos nitrogenados dos microrganismos ruminais deixam de ser atendidas em níveis dietéticos de $\mathrm{PB}$ inferiores a 6-8\%, comprometendo a utilização dos substratos energéticos disponíveis. Desta forma, a queda da fração Bp da FDN em níveis inferiores a $8,62 \%$ de PB (aproximadamente $8 \%$ ) não indica redução real, mas somente a transformação aparente de parte da fração potencialmente degradável em fração indegradável por deficiência de sistemas enzimáticos microbianos para degradar tal porção (Paulino et al., 2006; Sampaio, 2007). Assim, a dimensão real de Bp mantém-se constante, independentemente das condições ruminais ou do nível de proteína dietética, uma vez que é característica do substrato (Ørskov, 2000).

O comportamento verificado para as frações Bp e Ip confirma os resultados obtidos por Sampaio (2007), que encontrou redução da fração potencialmente degradável da FDN oriunda de forragem de baixa qualidade em níveis proteicos dietéticos inferiores a 7\%.

De forma similar, Ortiz-Rubio et al. (2007), ao trabalharem com bovinos alimentados com pontas de cana $(5,38 \%$ de $\mathrm{PB})$ que receberam níveis crescentes de compostos nitrogenados suplementares, verificaram ampliação da fração potencialmente degradável da MS da forragem basal em função da elevação do nível de PB na dieta. Tais evidências reforçam o conceito de energia latente salientado por Paulino et al. (2001), os quais afirmaram que, em condições de carência de compostos nitrogenados na dieta, parte dos substratos energéticos da forragem potencialmente utilizáveis deixam de ser efetivamente aproveitados por deficiência dos sistemas enzimáticos microbianos.

Comumente, na interpretação da dinâmica de degradação ruminal, considera-se que os eventos podem ser descritos por reação de primeira ordem, ou seja, estes são dependentes de um único pool (Mertens, 2005), pressupondo-se o substrato como limitante e o sistema enzimático microbiano como não-limitante. Dessa forma, as características intrínsecas do substrato seriam os únicos determinantes do processo de degradação, considerando-se excesso de enzimas no meio (Sampaio, 2007).
Contudo, o comportamento verificado para Bp e Ip permite inferir que duas fases distintas de interpretação da dinâmica de degradação podem ser definidas. Em concentrações superiores a 8\% de PB na dieta, a obtenção de estimativas da fração potencialmente degradável de forma integral (Fig. 1) indica que não ocorreram limitações quanto ao pool enzimático no rúmen, caracterizando, portanto, reação de primeira ordem (Mertens, 2005).

A obtenção de estimativas parciais de Bp em níveis de $\mathrm{PB}$ inferiores a $8 \%$ indica que $\mathrm{o}$ processo de degradação tornou-se limitado também em função dos sistemas enzimáticos no rúmen, e não só das características do substrato. Desta forma, a elevação do teor de PB da dieta indica ser a dinâmica de degradação da FDN no rúmen processo de segunda ordem (ou processo cinético de Michaelis-Menten) (Detmann et al., 2005; Mertens, 2005), ou seja, a deficiência de sistemas enzimáticos em níveis inferiores a $8 \%$ de PB implica reações de ordem zero, as quais são convertidas em ordem um à medida que compostos nitrogenados são adicionados ao meio. Sendo assim, a suplementação com compostos nitrogenados implica ampliação dos sistemas enzimáticos microbianos no ambiente ruminal (Sampaio, 2007).

Neste estudo, a concentração média diária de NAR (Tab. 2) apresentou comportamento linear crescente $(\mathrm{P}<0,05)$ em função dos níveis de $\mathrm{PB}$ da dieta $\left(\hat{\mathrm{Y}}=-7,3945+2,0980 \mathrm{X} ; \mathrm{r}^{2}=0,9209\right)$. A conversão do nível de PB na dieta em NAR por intermédio dessa equação permite inferir que a estabilização na estimativa de Bp (Fig. 1) ocorreu com o nível de 10,70mg NAR/dL, a qual poderia ser interpretada como a concentração mínima necessária para a manutenção adequada da atividade microbiana sobre a FDN da forragem basal. Este valor converge à recomendação de Leng (1990) $(10 \mathrm{mg} / \mathrm{dL})$ para maximização da degradação ruminal em animais alimentados com forragens tropicais de baixa qualidade.

Verificou-se efeito quadrático $(\mathrm{P}<0,05)$ para a taxa de degradação da fração potencialmente degradável da FDN (kd) em função dos níveis de $\mathrm{PB}$ da dieta $(\hat{\mathrm{Y}}=0,1345+0,009149 \mathrm{X}-$ $\left.0,00034176 X^{2} ; R^{2}=0,6769\right)$, com ponto crítico (resposta máxima) localizado sobre o nível de 13,39\% de PB. 
Este comportamento é semelhante ao verificado por Satter e Slyter (1974), que afirmaram que o efeito do rendimento microbiano e o da produção de proteína microbiana do substrato energético (os quais são diretamente dependentes das taxas de degradação e crescimento microbiano) resultam em resposta positiva, com elevação dos níveis de $\mathrm{PB}$ da dieta até limites em torno de 13 a $14 \%$, a partir dos quais aumentos na taxa de degradação não são mais obtidos.

As estimativas das taxas de degradação da FDN obtidas neste estudo encontram-se em patamares superiores aos comumente encontrados em forragens tropicais (Vieira et al., 1997; Campos et al., 2006; Casali et al., 2008). No entanto, estimativas similares às aqui relatadas foram obtidas por Sampaio (2007) ao alimentar bovinos com forragem tropical de baixa qualidade. Ressalta-se que, tanto na presente situação experimental, como na situação avaliada por Sampaio (2007), observaram-se condições dietéticas atípicas, nas quais a FDN oriunda de forragem de baixa qualidade constituía, basicamente, a única fonte de carboidratos para o crescimento microbiano, com ingestão de carboidratos não-fibrosos (CNF) abaixo da contribuição metabólica fecal (Sampaio, 2007; Lazzarini, 2007).

Sabe-se que a presença de CNF no meio de crescimento microbiano gera efeitos negativos sobre a degradação da FDN, fenômeno denominado "efeito carboidrato" (Mould et al., 1983; Arroquy et al., 2005; Costa et al., 2008), fato que parece estar associado à liberação de compostos inibidores pelos microrganismos que degradam o amido (El-Shazly et al., 1961) ou a competições por substratos essenciais entre grupos de espécies microbianas (Coelho da Silva e Leão, 1979). Desta forma, as condições ruminais conferidas neste estudo e no trabalho realizado por Sampaio (2007) poderiam ter levado à eliminação do "efeito carboidrato", fato que teria permitido o desenvolvimento predominante de bactérias fibrolíticas, sem a presença de interações de inibição ou competição com bactérias que degradam CNF, e possibilitado a elevação das taxas de degradação. Contudo, ressalta-se que, mesmo apresentando estimativas elevadas, a tendência observada em função dos níveis de PB, como discutido anteriormente, garante a observação de estímulos sobre o crescimento dos microrganismos com a suplementação com compostos nitrogenados (Tab. 2).

Não foram verificados efeitos dos níveis de PB na dieta sobre as estimativas de latência discreta $(\mathrm{P}>0,05)$ (Tab. 2).

O comportamento da fração efetivamente degradada (FED) da FDN (Tab. 2) em função dos níveis de PB pode ser visualizado por intermédio da função LRP apresentada na Fig. 2 $(\mathrm{P}<0,05)$. Evidenciou-se elevação da FED ao patamar de $47,30 \%$ da FDN a partir do nível de $8,63 \%$ de $\mathrm{PB}$ na dieta, complementando as afirmações relacionadas ao comportamento de Bp.

Segundo Paulino et al. (2006), embora a fração potencialmente degradável da FDN possa ser contabilizada como recurso energético para produção animal, deve-se relevar que esta constitui conceito assintótico, ou seja, somente pode ser considerado válido se avaliado sob escala de tempo infinita. Contudo, em termos práticos, os eventos de degradação ruminal ocorrem em escalas de tempo finitas. Assim, a otimização dos recursos nutricionais basais, no contexto da interação com os recursos dos suplementos, deve se calcar na máxima aproximação entre a FED e a fração potencialmente degradável da FDN (Bp), sem, contudo, implicar comprometimento sobre o consumo voluntário (Paulino et al., 2006).

A associação entre o fluxo ruminal de partículas fibrosas (L) (Tab. 2) e o nível de PB na dieta pôde ser descrita por função LRP $(\mathrm{P}<0,05)$, com ponto crítico para o início do platô localizado sobre o nível de 7,68\% de PB (Fig. 3). Esse comportamento parece refletir a ampliação aparente em Ip em função da deficiência de compostos nitrogenados no ambiente ruminal, uma vez que a fração indegradável apresenta, naturalmente, maior efeito de repleção ruminal, pois somente pode deixar o rúmen por passagem, ao contrário do observado para a fração potencialmente degradável, a qual é retirada do ambiente ruminal por passagem e degradação (Waldo et al., 1972). 


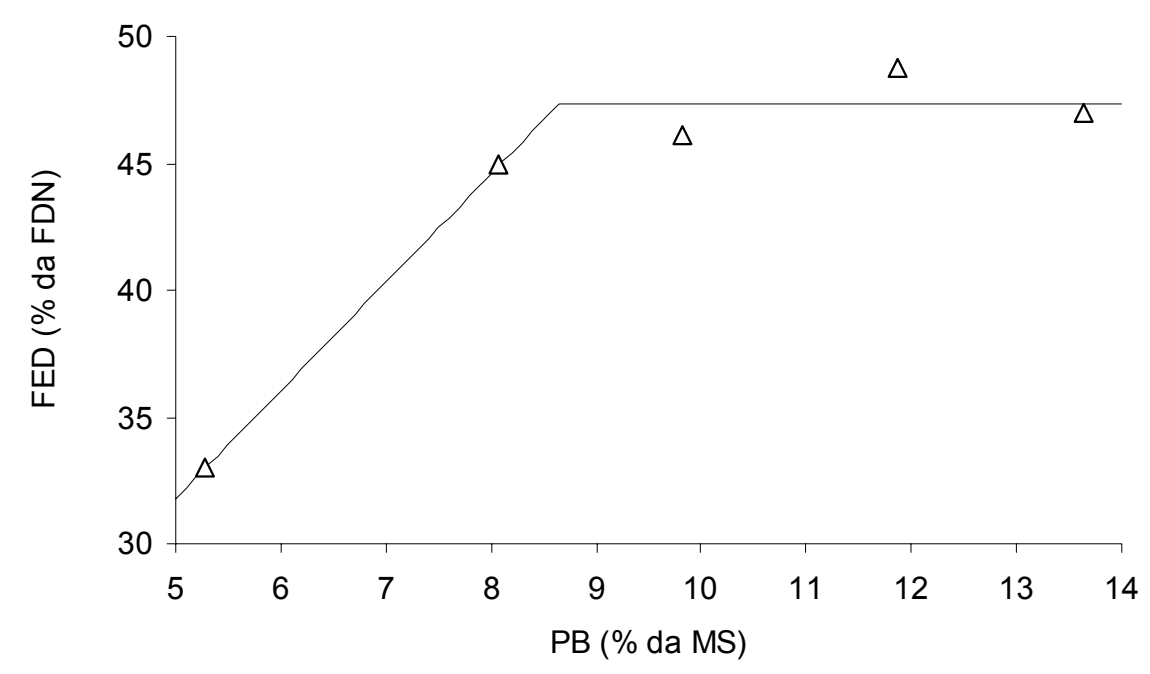

Figura 2. Comportamento descritivo e função ajustada para a relação entre o nível de proteína bruta (PB) da dieta e a estimativa da fração efetivamente degradada (FED) da fibra em detergente neutro (FDN) $(\hat{\mathrm{Y}}=$ $\left.10,4357+4,268 \mathrm{X} ; \forall \mathrm{X} \leq 8,6384 ; \hat{\mathrm{Y}}=47,3033 ; \forall \mathrm{X}>8,6384 ; \mathrm{R}^{2}=0,9760\right)$.

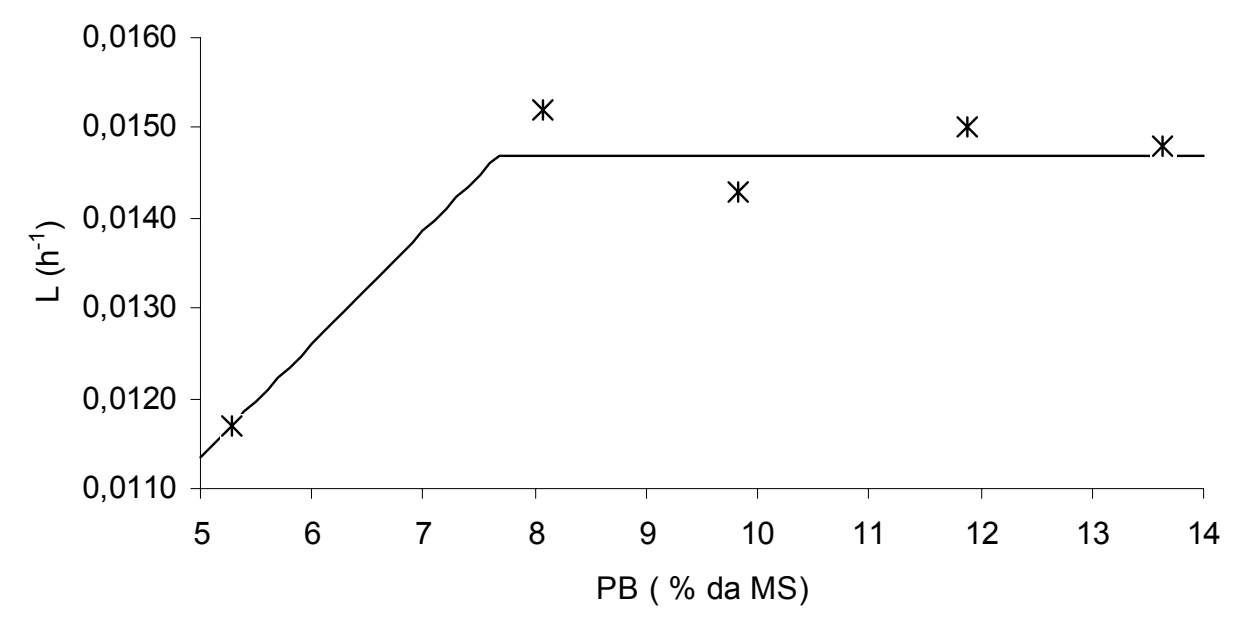

Figura 3. Comportamento descritivo e função ajustada para a relação entre o nível de proteína bruta (PB) da dieta e a estimativa do parâmetro taxa tempo-dependente relativo ao fluxo ruminal de partículas (L) ( $\hat{\mathrm{Y}}$ $\left.=0,0051+0,00125 \mathrm{X} ; \forall \mathrm{X} \leq 7,6800 ; \hat{\mathrm{Y}}=0,0147 ; \forall \mathrm{X}>7,6800 ; \mathrm{R}^{2}=0,9637\right)$.

Por serem parâmetros obtidos a partir da recíproca de $L$ (equações 2 e 3), o tempo médio de retenção no rúmen-retículo $(\hat{\mathrm{Y}}=30,64020$ $21,400 \mathrm{X} ; \forall \mathrm{X} \leq 7,5875 ; \hat{\mathrm{Y}}=144,0300 ; \forall \mathrm{X}>$ 7,$\left.5875 ; \mathrm{R}^{2}=0,9484\right)$ e o tempo médio de retenção total $(\hat{\mathrm{Y}}=312,8226-21,461 \mathrm{X} ; \forall \mathrm{X} \leq$ 7,$5524 ; \hat{\mathrm{Y}}=150,7433 ; \forall \mathrm{X}>7,5524 ; \mathrm{R}^{2}=$ $0,9493)$ apresentaram comportamento similar ao fluxo de partículas $(\mathrm{P}<0,05)$, ao passo que o tempo médio de trânsito no intestino $(\tau)$ não foi influenciado pelos níveis de $\mathrm{PB}$ na dieta $(\mathrm{P}>0,05)$ (Tab. 2).

Os níveis de $\mathrm{PB}$ na dieta não influenciaram $(\mathrm{P}>0,05)$ o efeito de repleção ruminal atribuído à fração potencialmente degradável da $\mathrm{FDN}\left(\mathrm{RR}_{1}\right)$, possível reflexo das altas taxas de degradação observadas (Tab. 2). Todavia, o efeito de 
repleção ruminal atribuído à fração indegradável da FDN $\left(\mathrm{RR}_{2}\right)$ apresentou relação LRP com os níveis de $\mathrm{PB}(\mathrm{P}<0,05)$, com ponto crítico para o início do platô localizado sobre o nível de 8,00\% de PB (Fig. 4). Como o efeito de repleção ruminal total da FDN $\left(R_{t}\right)$ é composto pela soma das variáveis $R_{1}$ e $R_{2}$, e a segunda compõe maior porção de RRt (Tab. 2), verificouse comportamento similar a $\mathrm{RR}_{2}$ para $\mathrm{RR}_{\mathrm{t}}(\hat{\mathrm{Y}}=$ 201,3009-15,779X; $\forall \mathrm{X} \leq 8,0088 ; \hat{\mathrm{Y}}=$ 74,$\left.9333 ; \forall \mathrm{X}>8,0088 ; \mathrm{R}^{2}=0,9805\right)$.

O desaparecimento da FDN do ambiente ruminal constitui processo tempo-dependente, no qual se integram as velocidades de degradação da fração potencialmente degradável da FDN e de retirada das frações não-degradada e indegradável da FDN (FDNi) do ambiente ruminal (Ellis et al., 1994), as quais, em conjunto com a baixa densidade da FDN, constituem os principais determinantes do consumo voluntário sob dietas com predomínio de forragem (Detmann et al.,
2003). Nesse contexto, a dinâmica do desaparecimento da FDN do ambiente ruminal pode ser mensurada de forma integrada por sua capacidade de repleção ruminal (Waldo et al., 1972).

Pressupondo-se condições de steady state no ambiente ruminal, pode-se assumir que, em dietas com predomínio de alimentos fibrosos, como em animais em pastejo nos trópicos, a massa residente de FDN no rúmen seja representada por um valor constante (Ellis et al., 1994). Desta forma, novas entradas de substratos fibrosos oriundos da forragem basal somente ocorrerão quando parte da massa residente for removida do ambiente por degradação ou passagem. Assim, a maximização da utilização da FDN potencialmente degradável disponível ao pastejo tem como ponto primário a maximização de seu input no ambiente ruminal, o qual pode também ser entendido como a minimização do efeito de repleção ruminal (Paulino et al., 2006).



Figura 4. Comportamento descritivo e função ajustada para a relação entre o nível de proteína bruta (PB) da dieta e a estimativa do efeito de repleção ruminal atribuído à fração indegradável da fibra em detergente neutro (FDN) (RR2) $(\hat{\mathrm{Y}}=200,5751-16,0460 \mathrm{X} ; \forall \mathrm{X} \leq 8,0046 ; \hat{\mathrm{Y}}=72,1300 ; \forall \mathrm{X}>8,0046$; $\mathrm{R}^{2}=0,9826$ ).

Segundo os resultados expressos na Tab. 2, verifica-se que $\mathrm{RR}_{2}$ representou de 96,0 a $98,2 \%$ de $R_{\mathrm{t}}$. Logo, para que se eleve o consumo de FDN da forragem basal, a dinâmica ruminal da fração indegradável da FDN deve ser considerada prioritária no entendimento da interação entre forragem e suplemento. Embora tenha se verificado estabilidade em $\mathrm{RR}_{2}$ a partir de $8 \%$ de $\mathrm{PB}$, os resultados aqui obtidos permitem indicar que a maximização do consumo de FDN (CFDN) ocorreu sobre 11,08\% de $\mathrm{PB}\left(\hat{\mathrm{Y}}=6,8116+1,65517 \mathrm{X}-0,07467 \mathrm{X}^{2} ; \mathrm{R}^{2}\right.$ $=0,9602)$. Resultados similares foram obtidos por Sampaio (2007). Sampaio (2007) e Lazzarini (2007) evidenciaram que o consumo de FDNi oriundo de forragem de baixa qualidade foi 
maximizado em níveis entre 10 e $11 \%$ de PB. Assim, este comportamento corrobora o fato de a retirada dos resíduos indegradáveis assumir papel preponderante na maximização do consumo de forragem de baixa qualidade (Sampaio, 2007).

Segundo Paulino et al. (2006), o consumo de FDN da forragem basal deve ser maximizado em sistemas de produção de animais em pastejo, uma vez que constitui a fonte de energia de menor custo. Neste contexto, a inspeção das correlações lineares entre as variáveis avaliadas neste estudo (Tab. 3) permitiu evidenciar que o CFDN mostrou-se positivamente correlacionado $(\mathrm{P}<0,05)$ com a taxa de passagem ruminal de partículas fibrosas (L), o que, indiretamente, resultou em associação negativa com o efeito de repleção ruminal atribuído à fração indegradável da FDN $(\mathrm{P}<0,05)$. Esse comportamento indica que a retirada de FDNi do sistema ruminal parece constituir meta prioritária para a ampliação do consumo de FDN a partir de forragens basais de baixa qualidade.

A correlação positiva $(\mathrm{P}<0,05)$ entre a concentração de NAR e a taxa de passagem de partículas fibrosas implicou diretamente na observação de associação positiva $(\mathrm{P}<0,05)$ entre NAR e CFDN (Tab. 3).

Desta forma, a associação do comportamento das correlações acima descritas indica que a suplementação com compostos nitrogenados, ao implementar níveis adequados de NAR, favorece a otimização do consumo voluntário de substratos fibrosos oriundos de forragem basal de baixa qualidade principalmente por influenciar negativamente o efeito de repleção ruminal da fração indegradável da FDN.

Tabela 3. Coeficientes de correlação linear de Pearson entre o consumo de fibra em detergente neutro (FDN) e a concentração de nitrogênio amoniacal ruminal (NAR) e os parâmetros das dinâmica de trânsito e degradação da FDN

\begin{tabular}{ccc}
\hline Variável & Consumo de FDN (g/kg PV) & NAR (mg/dl) \\
\hline Bp (\%) & $0,3951^{\mathrm{ns}}$ & $0,3832^{\mathrm{ns}}$ \\
$\mathrm{Ip}(\%)$ & $-0,3951^{\mathrm{ns}}$ & $-0,3832^{\mathrm{ns}}$ \\
$\mathrm{KD}\left(\mathrm{h}^{-1}\right)$ & $-0,0262^{\mathrm{ns}}$ & $-0,2528^{\mathrm{ns}}$ \\
$\mathrm{LAG}(\mathrm{h})$ & $0,0302^{\mathrm{ns}}$ & $0,3240^{\mathrm{ns}}$ \\
$\mathrm{L}\left(\mathrm{h}^{-1}\right)$ & $0,6317^{*}$ & $0,6263^{*}$ \\
$\tau(\mathrm{h})$ & $-0,2325^{\mathrm{ns}}$ & $-0,1169^{\mathrm{ns}}$ \\
TMRR (h) & $-0,6269^{*}$ & $-0,6366^{*}$ \\
TMRT (h) & $-0,6253^{*}$ & $-0,6318^{*}$ \\
FED $(\%)$ & $0,3884^{\mathrm{ns}}$ & $0,3602^{\mathrm{ns}}$ \\
$\mathrm{RR}_{1}(\mathrm{~h})$ & $0,3059^{\mathrm{ns}}$ & $0,5773^{*}$ \\
$\mathrm{RR}_{2}(\mathrm{~h})$ & $-0,6240^{*}$ & $-0,5723^{*}$ \\
$\mathrm{RR}_{\mathrm{t}}(\mathrm{h})$ & $-0,6236^{*}$ & $-0,5626^{*}$ \\
Consumo de FDN (g/kg PV) & --- & $0,5857^{*}$ \\
\hline
\end{tabular}

(ns) e $(*)$ : não-significativo e significativo pelo teste $\mathrm{t}(\alpha=0,05)$, respectivamente. As estimativas de correlações foram ajustadas para os efeitos fixos de animal e período. Bp: fração potencialmente degradável padronizada da FDN; Ip: fração indegradável padronizada da FDN; kd: taxa de degradação da fração potencialmente degradável da FDN; LAG: latência discreta; FED: fração efetivamente degradada da FDN; L: parâmetro taxa tempo-dependente relativo ao fluxo ruminal de partículas fibrosas; $\tau$ : tempo de trânsito intestinal; TMRR: tempo médio de retenção no rúmenretículo; TMRT: tempo médio de retenção total; $\mathrm{RR}_{1}$ : efeito de repleção ruminal da fração potencialmente degradável da FDN; $R_{2}$ : efeito de repleção ruminal da fração indegradável da FDN; $R_{t}$ : efeito de repleção ruminal total da FDN.

\section{CONCLUSÕES}

Níveis de proteína bruta próximos a $8 \%$, com base na matéria seca, são necessários para que os microrganismos ruminais apresentem capacidade plena de utilização dos componentes fibrosos de forragem basal de baixa qualidade. A taxa de passagem de partículas fibrosas e, consequentemente, o efeito de repleção ruminal da fibra em detergente neutro indigestível constituem os principais entraves ao consumo de componentes fibrosos, o qual é otimizado sob níveis proteicos próximos a $11 \%$. 


\section{REFERÊNCIAS BIBLIOGRÁFICAS}

ALLEN, M.S. Physical constrains on voluntary intake of forages by ruminants. J. Anim. Sci., v.74, p.3063-3075, 1996.

ARROQUY, J.I.; COCHRAN R.C.; NAGARAJA, T.G. et al. Effect of types of nonfiber carbohydrates on in vitro forage fiber digestion of low-quality grass hay. Anim. Feed Sci. Technol., v.120, p.93-106, 2005.

CAMPOS, P.R.S.S.; VALADARES FILHO, S.C.; CECON, P.R. et al. Estudo comparativo da cinética de degradação ruminal de forragens tropicais em bovinos e ovinos. Arq. Bras. Med. Vet. Zootec., v.58, p.1181-1191, 2006.

CASALI, A.O.; DETMANN, E.; VALADARES FILHO, S.C. et al. Influência do tempo de incubação e do tamanho de partículas sobre os teores de compostos indigestíveis em alimentos e fezes bovinas obtidos por procedimentos in situ. Rev. Bras. Zootec., v.37, p.335-342, 2008.

COELHO da SILVA, J.F.; LEÃO, M.I. Fundamentos de nutrição dos ruminantes. Piracicaba: Livroceres, 1979. 380p.

COSTA, V.A.C.; DETMANN, E.; VALADARES FILHO, S.C. Degradação in vitro da fibra em detergente neutro de forragem tropical de baixa qualidade em função de suplementação com proteína e/ou carboidratos. Rev. Bras. Zootec., v.37, p.494-503, 2008.

DETMANN, E.; PAULINO, M.F.; CABRAL, L.S. et al. Simulação e validação de parâmetros da cinética digestiva em novilhos mestiços suplementados a pasto por intermédio de sistema in vitro de produção de gases. Rev. Bras. Zootec., v.34, p.2112-2122, 2005.

DETMANN, E.; QUEIROZ, A.C.; CECON, P.R. et al. Consumo de fibra em detergente neutro por bovinos em confinamento. Rev. Bras. Zootec., v.32, p.1763-1777, 2003.

EL-SHAZLY, K; DEHORITY, B.A.; JOHSON, R.R. Effect of starch on the digestion of cellulose in vitro and in vivo by rumen microorganisms. $J$. Anim. Sci., v.20, p.268-273, 1961.

ELLIS, W.C.; MATIS, J.H.; HILL, T.M. et al. Methodology for estimating digestion and passage kinetics of forages. In: FAHEY Jr., G.C. (Ed). Forage quality, evaluation, and utilization.
Madison, WI: American Society of Agronomy, 1994. p.682-756.

LAZZARINI, I. Consumo, digestibilidade $e$ dinâmicas de trânsito e degradação da fibra em detergente neutro em bovinos alimentados com forragem tropical de baixa qualidade $e$ compostos nitrogenados. 2007. 53f. Dissertação (Mestrado) Universidade Federal de Viçosa, Viçosa, MG.

LENG, R.A. Factors affecting the utilization of "poor-quality" forages by ruminants particularly under tropical conditions. Nutr. Res. Rev., v.3, p.277-303, 1990.

McCOLLUM, F.T.; GALYEAN, M.L. Influence of cottonseed meal supplementation on voluntary intake, rumen fermentation and rate of passage of prairie hay in beef steers. J. Anim. Sci., v.60, p.570-577, 1985.

MERTENS, D.R. Gravimetric determination of amylase-treated neutral detergent fiber in feeds with refluxing in beakers or crucibles: collaborative study. J. AOAC Int., v.85, p.12171240, 2002.

MERTENS, D.R. Rate and extent of digestion. In: DIJKSTRA, J.; FORBES, J.M.; FRANCE, J. (Eds). Quantitative aspects of ruminant digestion and metabolism. 2.ed. Wallingford: CABI Publishing, 2005. p.13-47.

MOULD, F.L.; ØRSKOV, E.R.; MANN, S.O. Associative effects of mixed feeds. 2. The effect of dietary additions of bicarbonate salts on the voluntary intake and digestibility of diets containing various proportions of hay and barley. Anim. Feed Sci. Technol., v.10, p.15-25, 1983.

MYERS, R.H. Classical and modern regression with applications. Boston: PWS-Kent Publishing, 1990. 488p.

ØRSKOV, E.R. The in situ technique for the estimation of forage degradability in ruminants. In: GIVENS, D.I.; OWEN, E.; AXFORD, R.F.E. et al. (Eds). Forage evaluation in ruminant nutrition. London: CAB International, 2000. p.175-188.

ØRSKOV, E.R.; McDONALD, I. The estimation of protein degradability in the rumen from incubation measurements of feed weighted according to rate passage. J. Agric. Sci., v.92, p.499-503, 1979. 
ORTIZ-RUBIO, M.A.; ØRSKOV, E.R.; MILNE, J. et al. Effect of different sources of nitrogen on in situ degradability and feed intake of Zebu cattle fed sugarcane tops (Saccharum officinarum). Anim. Feed Sci. Technol., v.139, p.143-158, 2007.

PAULINO, M.F.; DETMANN, E.; VALADARES FILHO, S.C. Suplementação animal em pasto: energética ou proteica? In: SIMPÓSIO SOBRE MANEJO ESTRATÉGICO DA PASTAGEM, 3. 2006, Viçosa. Anais... Viçosa: SIMFOR, 2006. p.359-392.

PAULINO, M.F.; DETMANN, E.; ZERVOUDAKIS, J.T. Suplementos múltiplos para recria e engorda de bovinos em pastagens. In: SIMPÓSIO DE PRODUÇÃO DE GADO DE CORTE, 2. 2001, Viçosa. Anais... Viçosa: SIMCORTE, 2001. p.187-233.

SAMPAIO, C.B. Consumo, digestibilidade e dinâmica ruminal em bovinos alimentados com forragem tropical de baixa qualidade suplementados com compostos nitrogenados. 2007. 53f. Dissertação (Mestrado) Universidade Federal de Viçosa, Viçosa, MG.

SATTER, L.D.; SLYTER, L.L. Effect of ammonia concentration on rumen microbial protein production in vitro. Br. J. Nutr., v.32, p.199-208, 1974.

SILVA, D.J.; QUEIROZ, A.C. Análise de alimentos: Métodos químicos e biológicos. 3.ed. Viçosa: Editora UFV, 2002. 235p.
SOUZA, G.S. Introdução aos modelos de regressão linear e não-linear. Brasília: EmbrapaSPI, 1998. 505p.

UDÉN, P.; COLUCCI, P.E.; VAN SOEST, P.J. Investigation of chromium, cerium and cobalt as markers in digesta. Rate of passage studies. $J$. Sci. Food Agric., v.31, p.625-632, 1980.

Van MILGEN, J.; MURPHY, M.R.; BERGER, L.L. et al. A compartmental model to analyze ruminal digestion. J. Dairy Sci., v.74, p.25152529, 1991.

Van SOEST, P.J. Nutritional ecology of the ruminant. 2.ed. Ithaca: Cornell University Press. 1994. 476p.

VIEIRA, R.A.M.; PEREIRA, J.C.; MALAFAIA, A.M. et al. The influence of elephant grass (Pennisetum purpureum Schum. Mineiro variety) growth on the nutrient kinetics in the rumen. Anim. Feed Sci. Technol., v.66, p.197-210, 1997.

WILLIANS, C.H.; DAVID, D.J.; IISMA, O. The determination of chromic oxide in faeces samples by atomic absorption spectrophotometry. J. Agric. Sci., v.59, p.381385, 1962.

WALDO, D.R.; SMITH, L.W.; COX, E.L. Model of cellulose disappearance from the rumen. J. Dairy Sci., v.55, p.125-129, 1972. 